\title{
The murine winged helix transcription factors, Foxc1 and Foxc2, are both required for cardiovascular development and somitogenesis
}

\author{
Tsutomu Kume, HaiYan Jiang, Jolanta M. Topczewska, and Brigid L.M. Hogan ${ }^{1}$ \\ Howard Hughes Medical Institute and Department of Cell Biology, Vanderbilt University Medical Center, \\ Nashville, Tennessee 37232, USA
}

\begin{abstract}
The murine Foxc1/Mf1 and Foxc2/Mfh1 genes encode closely related forkhead/winged helix transcription factors with overlapping expression in the forming somites and head mesoderm and endothelial and mesenchymal cells of the developing heart and blood vessels. Embryos lacking either Foxc1 or Foxc2, and most compound heterozygotes, die pre- or perinatally with similar abnormal phenotypes, including defects in the axial skeleton and cardiovascular system. However, somites and major blood vessels do form. This suggested that the genes have similar, dose-dependent functions, and compensate for each other in the early development of the heart, blood vessels, and somites. In support of this hypothesis, we show here that compound Foxc1; Foxc2 homozygotes die earlier and with much more severe defects than single homozygotes alone. Significantly, they have profound abnormalities in the first and second branchial arches, and the early remodeling of blood vessels. Moreover, they show a complete absence of segmented paraxial mesoderm, including anterior somites. Analysis of compound homozygotes shows that Foxc1 and Foxc2 are both required for transcription in the anterior presomitic mesoderm of paraxis, Mesp1, Mesp2, Hes5, and Notch1, and for the formation of sharp boundaries of Dll1, Lfng, and ephrinB2 expression. We propose that the two genes interact with the Notch signaling pathway and are required for the prepatterning of anterior and posterior domains in the presumptive somites through a putative Notch/Delta/Mesp regulatory loop.
\end{abstract}

[Key Words: Forkhead/winged helix gene; Fox gene; mouse embryo; somite segmentation; cardiovascular development; Notch signaling pathway]

Received April 27, 2001; revised version accepted July 18, 2001.

Gastrulation of the vertebrate embryo sets the stage for two fundamental processes, cardiovascular development-the establishment of the heart and blood vessels (Harvey 1998; Srivastava and Olson 2000; Srivastava 2001), and somitogenesis-the reiterated subdivision of unsegmented paraxial mesoderm into paired epithelial somites flanking the midline /Gossler and Hrabe de Angelis 1998; Jiang et al. 1998; Dale and Pourquie 2000; Pourquie 2000). Genetic analysis in several model organisms has identified families of conserved genes essential for either cardiovascular development or somitogenesis. More rarely, some genes, such as Mesp1 and Mesp2 and Notch1 and Notch4, function in both processes. Here, we provide genetic evidence that the two mouse forkhead/winged helix genes, Foxc1 and Foxc2 (formerly Mf1 and $M f h 1$, respectively), encoding closely related Fox

${ }^{1}$ Corresponding author.

E-MAIL brigid.hogan@mcmail.vanderbilt.edu; FAX (615) 343-2033.

Article and publication are at http://www.genesdev.org/cgi/doi/10.1101/ gad.907301. transcription factors (Kaestner et al. 2000) with virtually identical DNA-binding domains, play similar, dose-dependent roles in the early development of the heart and blood vessels, as well as the somites. Significantly, embryos lacking the two genes show absence of both early vascular remodeling and segmented paraxial mesoderm and somites. Analysis of gene expression in these compound homozygous mutants suggests that the two forkhead proteins interact with the Notch signaling pathway.

Previous studies had established that Foxc1 and Foxc2 have overlapping transcription domains in many embryonic tissues. These include the paraxial, cephalic and nephrogenic mesoderm, somites, endothelial cells of the heart and blood vessels, and mesenchyme of the aortic arches, valves, and outflow tract (Iida et al. 1997; Hiemisch et al. 1998; Kume et al. 1998, 2000b; Swiderski et al. 1999; Winnier et al. 1999). Given this widespread expression, it was not unexpected to find that homozygous null mutants for each gene have a lethal phenotype with many developmental abnormalities. Foxc1 $1^{\text {lac }}$ homozy- 
gous mice die pre- and perinatally with haemorrhagic hydrocephalus and multiple skeletal, ocular, and genitourinary defects. Although early remodeling of blood vessels is mostly normal, they do have cardiovascular defects, most notably, interruption or coarctation of the aortic arch (Kume et al. 1998, 2000b; Kidson et al. 1999; Winnier et al. 1999; Smith et al. 2000). Mutations in human FOXC1 (FKHL7) are associated with the dominantly inherited Axenfeld-Rieger anomaly (ARA). This is characterized by congenital glaucoma, and the dysgenesis of the anterior chamber of the eye in affected patients resembles that of heterozygous Foxc1 mice (Mears et al. 1998; Nishimura et al. 1998; Smith et al. 2000). Foxc2 null mutants also die pre- and perinatally with skeletal, genitourinary, and cardiovascular defects similar to those of Foxc1 homozygotes (Iida et al. 1997; Winnier et al. 1997, 1999; Kume et al. 2000b). Mutations in human FOXC2 (FKHL14) are responsible for the autosomal-dominant syndrome, Lymphedema-distichiasis (LD), suggesting a role for the gene in the development of the lymphatic system (Fang et al. 2000). To determine whether Foxc1 and Foxc2 interact genetically and compensate for each other in the single mouse mutants, we generated compound heterozygotes. Unexpectedly, we found that most (but not all) of these mice die pre- and perinatally with a similar spectrum of cardiovascular, genitourinary, and eye abnormalities as those seen in each single homozygous null mutant (Winnier et al. 1999; Kume et al. 2000b; Smith et al. 2000).

The defects that Foxc1 and Foxc2 homozygotes display in the axial skeleton include reduced centra of the vertebrae, incomplete dorsal neural arches, and fused ribs (Gruneberg 1943; Iida et al. 1997; Winnier et al. 1997; Kume et al. 1998). However, these abnormalities are relatively mild considering the early onset and high level of expression of the genes in the paraxial mesoderm, presomitic mesoderm (PSM), and developing somites (Miura et al. 1993; Sasaki and Hogan 1993). Taken together, the phenotype of homozygous null embryos and the nonallelic noncomplementation of the two null mutations suggest that the Foxc1 and Foxc2 play similar, dose-dependent roles in cardiovascular development and somitogenesis. This led to the hypothesis that inactivation of both genes would give a much more severe phenotype and reveal the earliest stages at which both genes are required. It is this hypothesis that we have tested in this study.

The process of somitogenesis can be divided into a number of specific steps, including the establishment of a prepattern of presumptive somites in the anterior PSM, the formation of a boundary between the posterior of the forming somite and the anterior of the next presumptive somite, and complete epithelialization of the newly formed somite. At present, no single model completely accounts for the sequential accomplishment of these steps (for reviews, see Collier et al. 2000; Dale and Pourquie 2000; Schnell and Maini 2000). According to one general model-the clock-and-wavefront model-cells in the PSM oscillate synchronously between alternate states under the influence of a cell-autonomous segmen- tation clock. Each state is associated with on or off expression of Notch pathway genes, for example, Lunatic fringe ( $L f n g$ ) and members of the Hairy/Enhancer of split family of bHLH transcription factors (Forsberg et al. 1998; Aulehla and Johnson 1999; Jouve et al. 2000). A hypothetical wave of maturation (the wave-front signal), possibly propagated posteriorly from the most recently formed somite, slows the oscillations anteriorly, resulting in waves of gene expression that sweep through the PSM from posterior to anterior. At the most anterior, oscillations cease and somite formation is initiated, resulting in the establishment of alternating bands of cells corresponding to presumptive somites. Notch pathway signaling within the presumptive somites (known as S-1 and S-2) further refines domains about one-half of a somite wide, apparently demarcating cells with anterior (A) and posterior $(\mathrm{P})$ somite fates. Recent research in the mouse suggests that the establishment and maintenance of this $\mathrm{A} / \mathrm{P}$ polarity or prepattern involves a feedback loop between Notch1, Dll1, and the bHLH transcription factor, Mesp2. In Mesp2 null mutants, for example, D111 is not down-regulated in the anterior domain of the presumptive somites and the morphogenesis of somites does not proceed normally (Saga et al. 1997; Takahashi et al. 2000). The final stage of somite formation involves generation of a morphological boundary between the posterior cells of S-1 and the anterior cells of S-2. This requires ephrin/Eph-signaling pathway genes (Durbin et al. 1998, 2000; Holder and Klein 1999).

Embryos lacking individual genes of the Notch-signaling pathway have defects in both somitogenesis and cardiovascular development (Barrantes et al. 1999; Donoviel et al. 1999; Krebs et al. 2000). These defects are more profound in compound null mutants lacking two closely related genes, for example, Notch1 and Notch4 (Krebs et al. 2000). Significantly, compound mutants lacking both presenilin1 and presenilin2 (ps1; ps2) genes, encoding intracellular proteins required for Notch function, lack any segmented somites, have defects in head mesenchyme and heart morphogenesis, and have a small second branchial arch (Donoviel et al. 1999). Here, we show that the phenotype of compound Foxc1; Foxc2 homozygotes is more abnormal than that of either single mutant, and is similar to that of $p s 1$; ps2 compound mutants. On the basis of this phenotype and marker gene analysis, we conclude that the two Fox genes are important new components of the genetic circuitry regulating somitogenesis and early cardiovascular development. Moreover, they appear to function by interacting with the Notch signaling pathway.

\section{Results}

Expression of Foxc1 and Foxc2 protein and RNA during somitogenesis and cardiovascular development

As shown previously, both Foxc1 and Foxc2 are transcribed in the PSM and somites, with highest expression in the anterior PSM (Fig. 1A,B). In contrast, immunohistochemistry showed that both proteins are expressed in 

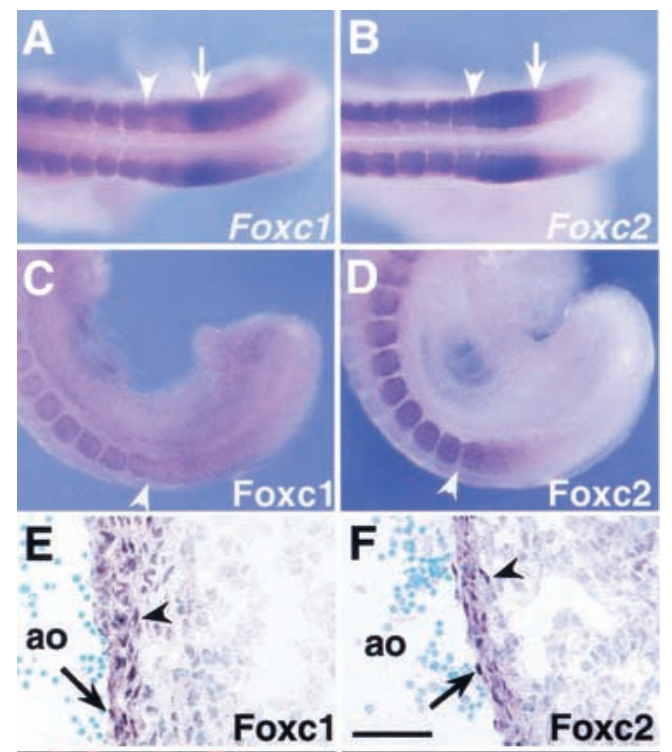

$\mathbf{F}$
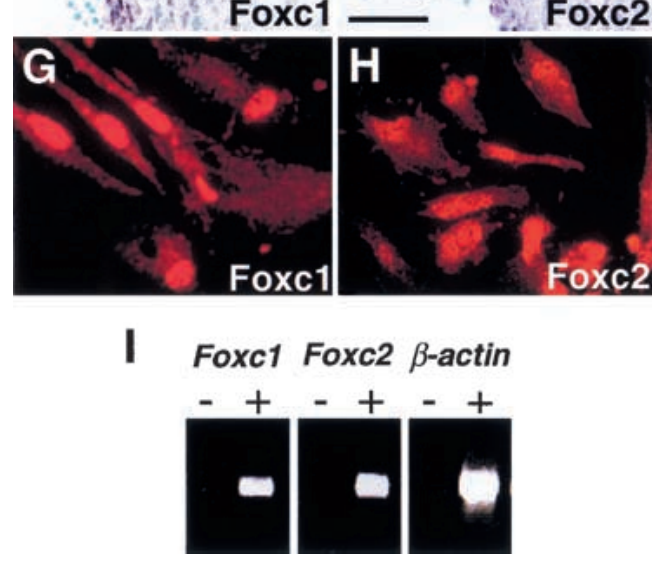

Figure 1. Expression of Foxc1 and Foxc2 RNA and protein. $(A, B)$ Whole-mount in situ hybridization of 9.5 dpc embryos. Both Foxc1 $(A)$ and Foxc2 $(B)$ are strongly expressed in the anterior PSM and somites. Arrowheads indicate boundary between the newly formed (S1) and forming (SO) somites. Arrows indicate the region of highest Foxc1 expression and boundary between high and low levels of Foxc2 expression in the PSM. $(C, D)$ Whole-mount immunohistochemistry of 9.5 dpc embryos using specific antibodies against Foxc1 $(C)$ and Foxc2 $(D)$. Compared with the RNA expression pattern $(A, B)$, the levels of two proteins in the PSM show a gradual posterior to anterior gradient. $(E, F)$ Section through dorsal aorta (ao) of a $12.5 \mathrm{dpc}$ embryo stained with specific antibodies against Foxc1 $(E)$ and Foxc2 $(F)$. The two proteins are localized in both the endothelial (arrow) and smooth muscle (arrowhead) cells. $(G, H)$ Immunostaining of human aortic smooth muscle cells using Foxc1 $(G)$ and Foxc2 $(H)$ antibodies. Both proteins are localized in the nuclei. (I) RTPCR analysis of Foxc1 and Foxc2 expression in the E9.5 yolk sac. (+) Plus reverse transcriptase; (-) without reverse transcriptase. Scale bar, $25 \mu \mathrm{m}$.

the PSM in a smooth gradient, from low levels in the posterior to highest levels in the anterior (Fig. 1C,D). Foxc1 and Foxc2 proteins are also localized in the endothelium and smooth muscle cells of blood vessels, tissues shown previously to express RNA (Fig. 1E,F). Moreover, we found that the two proteins are detected in nu- clei of human aortic smooth muscle cells in culture (Fig. $1 \mathrm{G}, \mathrm{H})$. In the yolk sac at 9.5 days post coitum (dpc), levels of transcripts of Foxc1 and Foxc2 are very low but can be detected by RT-PCR (Fig. 1I).

\section{Compound Foxc1-/- Foxc2 $^{-/-}$homozygous null mutants die around $9.0 \mathrm{dpc}$ with severe abnormalities in cardiovascular development.}

Although the viability of compound $\mathrm{Foxc1}^{+/-}$; $\mathrm{Foxc}^{+/-}$ heterozygotes is very low, some survive as adults. By interbreeding, we have obtained compound homozygotes at the expected ratio (1/16) (Fig. 2). These embryos die around 9.0-9.5 dpc with a much more severe phenotype than that of either single homozygote alone. The compound homozygotes are significantly smaller at 9.5 dpc than wild type and usually have an open anterior neural tube and occasionally an enlarged pericardial sac. Externally they completely lack a second branchial arch (BA) and the first BA is very small (Fig. 2A,B). Histological analysis shows a drastic disorganization of blood vessels and mesenchyme in the head, and large numbers of pycnotic mesenchyme cells in the region in which the second BAs would be expected (Fig. 2D,F). Although beating weakly, the heart is smaller and the myocardium less well developed than wild type (Fig. $2 \mathrm{H}$ ). In the trunk region, there is a striking absence of epithelialized somites, including dermamyotome (Fig. 2K)

Whole-mount PECAM-1 immunostaining reveals that most blood vessels in compound homozygotes are still organized into plexi that have undergone very little remodeling (Fig. 3A-D). A similar primitive vascular plexus is seen in the extraembryonic mesoderm of the mutant yolk sac (Fig. 3E,F). Nevertheless, vascular smooth muscle cells are differentiated, as judged by $\alpha$ smooth muscle cell actin expression (Fig. $3 \mathrm{H}$ ), and have been recruited around the endothelial cells (Fig. 3J).

\section{Compound homo/heterozygotes also have cardiovascular defects}

We also analyzed the cardiovascular system of compound homo/heterozygous mutant embryos. Compound Foxc1 $1^{-1-}$; Foxc2 $2^{+-}$mutant embryos die around $11.5 \mathrm{dpc}$. The phenotype of these embryos has not been studied in detail, but at $9.5 \mathrm{dpc}$ they have no obvious defects in remodeling of blood vessels (data not shown). In contrast, compound Foxc1 ${ }^{+/-}$; Foxc2 $2^{-/-}$mutant embryos die earlier, at around $10.5 \mathrm{dpc}$. They lack a second branchial arch and have extensive defects in the remodeling of the blood vessels in the head and body, as revealed by wholemount PECAM-1 staining (Fig. 4A-C), and have small and irregular shaped somites (data not shown).

We analyzed Foxc1 $1^{+/-}$; Foxc2 $2^{-/-}$embryos at $10.5 \mathrm{dpc}$ by ink injection into the heart to reveal the morphology of the BA arteries (Fig. 4). Variable and multiple abnormalities were detected among the five embryos studied, including an enlarged third BA artery with an ectopic branch (Fig. 4F, arrowhead and arrow, respectively), thin 


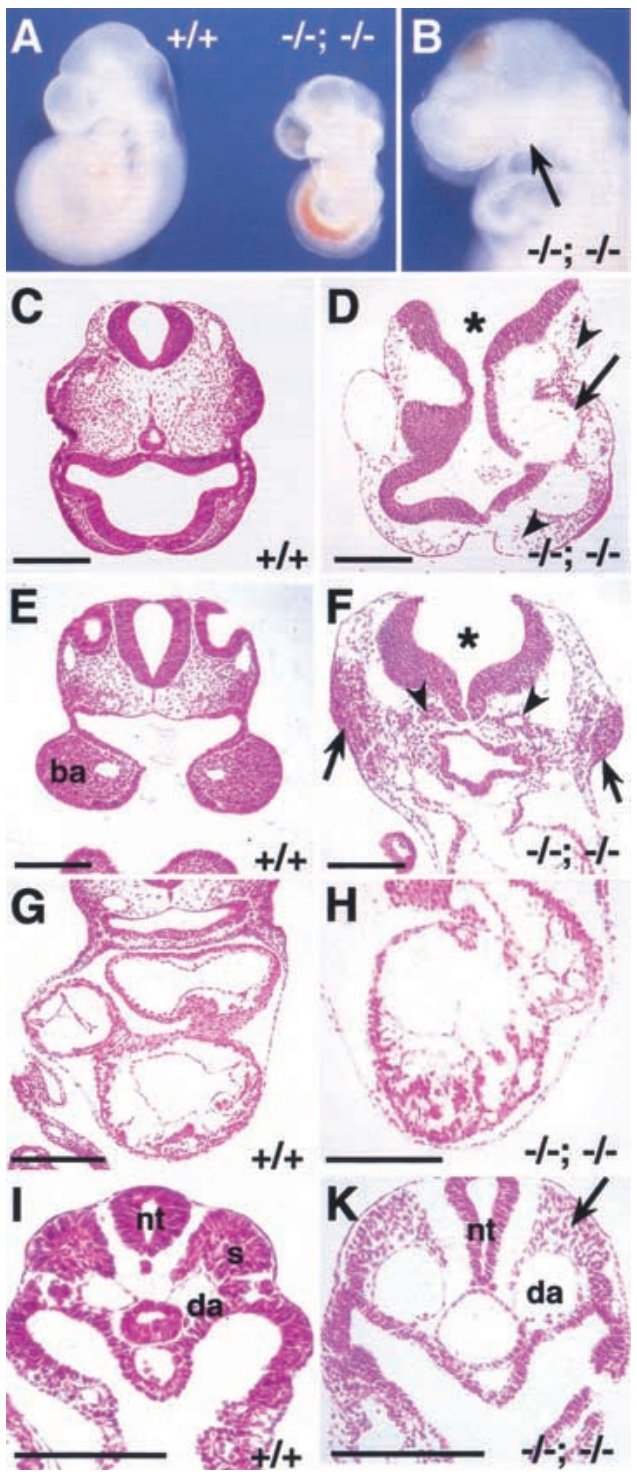

Figure 2. Compound Foxc1 $1^{-/-}$; Foxc2 $2^{-/-}$mutant embryos have numerous abnormalities. (A) Wild-type and compound homozygous mutant embryos at $9.5 \mathrm{dpc}$. Compound homozygote (right) is smaller than wild type and has blood accumulated in the dorsal aorta, probably because of a weakly beating heart. $(B)$ Compound homozygote at 9.0 dpc lacks a second branchial arch (BA) and has a small first BA (arrow). (C-K) Transverse sections at $9.0 \mathrm{dpc} .(C, D)$ Sections at the level of the head. Compared with the wild type $(C)$, the compound homozygote has a disorganized head structure, including an open neural tube (asterisk), sparse mesenchyme (arrowheads), and enlarged blood vessels (arrow). $(E, F)$ Sections at the level of the first BA. Although the compound homozygote has no visible second BA, there are local dense accumulations of mesenchymal cells with pycnotic nuclei ( $F$, arrows). Note the open neural tube (asterisk) and ectopic epithelial tubes that may represent endoderm that would have formed branchial pouches (arrowheads). $(G, H)$ Sections at the level of the heart. The compound homozygote has a small heart with disorganized myocardium $(H) .(I, K)$ Sections at the level of the trunk. Note absence of epithelial somites (arrow) and the dilated dorsal aortae in compound homozygote. (ba) Branchial arch; (da) dorsal aorta; (nt) neural tube; (s) somite. Scale bar, $100 \mu \mathrm{m}$.
BA arteries (Fig. 4H,I), and generally disorganized BA arteries (Fig. $4 \mathrm{~J}$ ).

Taken together, the results presented here show that the cardiovascular phenotypes of compound homozygotes and $\mathrm{FoxC1}^{+/-}$; Foxc2 ${ }^{-/-}$compound hetero/homozygous embryos are more severe than those of single homozygotes and compound heterozygotes.

\section{Compound Foxc1 ${ }^{-/-}$; Foxc2 $2^{-/-}$homozygous null mutants have no somites or segmented paraxial mesoderm}

A striking feature of the compound homozygotes is the complete absence of epithelial somites or segmented paraxial mesoderm, as judged by the morphology of embryos at the time when wild-type littermates have eight somites (Fig. 5A). This is confirmed by histological analysis (Fig. 5, cf. B and C). This result is important because individual homozygous null and compound homo/heterozygous null embryos clearly make epithelial somites, even though they may be abnormally shaped or the sclerotome derivatives later develop abnormally. Unlike most other mouse mutants in which only more posterior somites are defective (Barrantes et al. 1999; Yoon and Wold 2000), compound Foxc1; Foxc2 homozygotes lack somites $1-8$, suggesting that the defect is manifested as soon as somitogenesis begins.

To understand the primary defect in somitogenesis, we examined several genes associated with the patterning and differentiation of paraxial mesoderm and somites. In wild-type embryos, paraxis is expressed in the somites, as well as the anterior PSM (Burgess et al. 1995) and embryos lacking paraxis show no epithelialized somites (Burgess et al. 1996). In Foxc1 ${ }^{-1-}$ and $\mathrm{FoxC2}^{-/-}$single homozygotes, paraxis expression resembled that in wild type (data not shown). In contrast, in compound Foxc1; Foxc2 homozygotes, paraxis expression is not detected in the PSM and somite region, but is transcribed at very low levels anteriorly, adjacent to the neural tube (Fig. 5D). This suggests that Foxc1 and Foxc2 are upstream of paraxis during somite formation. In contrast, Mox1, which is first expressed in paraxial mesoderm at gastrulation and subsequently in the PSM and somites (Candia et al. 1992), is transcribed in compound homozygotes (Fig. 5E). pMesogenin1, which encodes a member of the bHLH transcription factor family, is expressed in the posterior PSM, in a domain mutually exclusive with those of Mesp1 and Mesp2 (see below) (Yoon and Wold 2000; Fig. 5F). Homozygous mutant embryos for $p M e s o g e n i n 1$ show complete failure of segmentation and somite formation in the trunk and tail, but do make anterior somites (Yoon and Wold 2000). In compound Foxc1; Foxc2 homozygotes, transcription of $p M e$ sogenin1 in the PSM is not affected (Fig. 5G). These data indicate that in compound homozygotes, mesodermal cells are specified as paraxial mesoderm even though they do not give rise to clearly segmented somites.

We next examined whether the paraxial mesoderm of compound homozygotes in the region in which somites 
Figure 3. Defects in remodeling of blood vessels in compound Foxc1 $1^{-1-}$; Foxc2 $2^{-1-}$ mutants. $(A-F)$ PECAM-1 immunostaining of endothelial cells at $9.5 \mathrm{dpc}$. In the wild-type embryo $(A)$ and at higher magnification in $(B)$, the blood vessels have remodeled to form clearly branched vessels (arrow in head), but in compound homozygote $(A)$ and at higher magnification $(C)$, only primitive plexi are present. Note absence of visible first and second BA arteries in compound homozygote compared with wild type ( $C$ vs. $B)$. (D) High magnification of $A$. Regular intersomitic blood vessels have sprouted from the dorsal aorta of wild-type embryo (arrows), but are not seen in compound homozygote (right). $(E, F)$ Yolk sac vasculature stained with PECAM-1 antibody at $9.0 \mathrm{dpc}$. In the wildtype yolk sac $(E)$, blood vessels have remodeled to form large (arrow) and small (arrowhead) vessels, whereas the vasculature of compound homozygote is a primitive meshwork $(F)$. $(G, H)$ Wholemount immunostaining of $9.0 \mathrm{dpc}$ yolk sacs for $\alpha$-smooth muscle cell actin (SMA). Smooth muscle cells are present around the blood vessels in both wild-type $(G$, arrow) and compound mutant yolk sacs $(H)$. The recruitment of smooth muscle is also
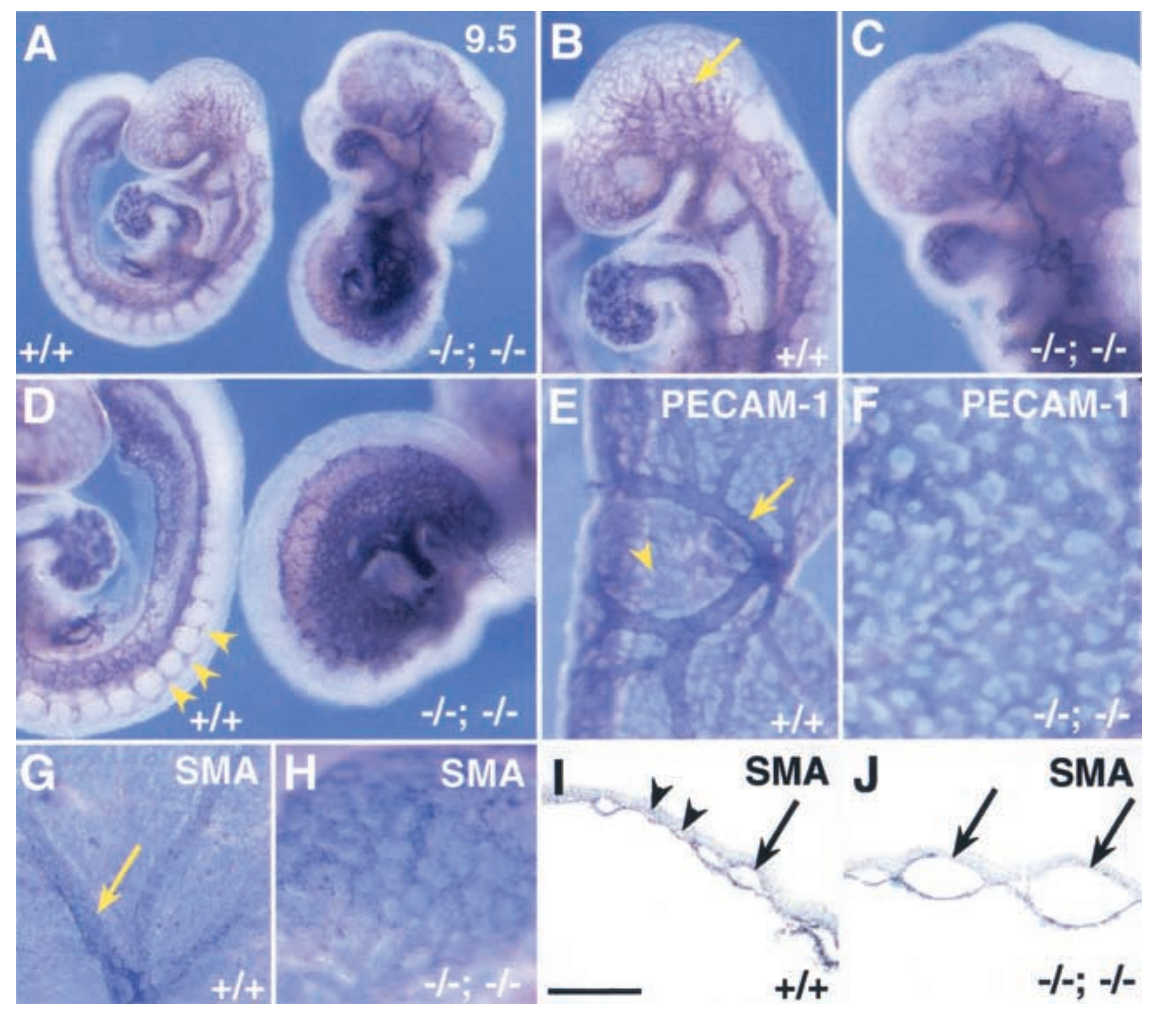

seen by $\alpha$-SMA immunostaining of sections $I$ and $J$. Note that the wild-type yolk sac has both small capillaries (arrowheads) and large vitelline collecting vessels (arrow, I), whereas the compound homozygous yolk sac has only enlarged vessels in a plexus (arrows, $J$ ). Scale bar, $50 \mu \mathrm{m}$.

would normally be present is specified into alternating bands of cells with anterior and posterior fates, even if there are no somites. Tbx18 and Uncx4.1 are genes normally specifically expressed in the anterior and posterior somites, respectively, both in wild-type embryos and single homozygotes (Mansouri et al. 1997; Kraus et al. 2001; Fig. 5H,J; data not shown). However, expression of neither gene is detected in compound homozygotes in the region in which the somites are normally present (Fig. 5I,K). Moreover, neither Pax1 nor MyoD are transcribed in this region either (Fig. 5P,R), suggesting that the paraxial mesoderm has a significant defect in differentiation. The ephrin/Eph-signaling pathway is normally involved in the formation of a distinct boundary between S0 and S-1 (where S0 is the forming somite and $\mathrm{S}-1$ is the next-to-be-formed somite), and expression of ephrinB2 is restricted to the posterior half of the somites (Bergemann et al. 1995; Fig. 5L). In compound homozygotes, transcription of ephrinB2 is detected in the region in which the somites are normally formed, but it is not present as a sharp band (Fig. 5M). This finding may be one reason for the failure to form normal boundaries.

Taken together, our results show that segmentation of the PSM is disrupted in compound homozygotes from the very beginning, even though at least some markers for the specification of paraxial mesoderm are expressed normally (Mox1 and pMesogenin1).
Compound homozygous mutants have defects in the Notch signaling pathway in the anterior PSM

There is compelling evidence that the Notch signaling pathway is required for establishing anterior and posterior cell fates in the anterior PSM (Gossler and Hrabe de Angelis 1998; Jiang et al. 1998; Barrantes et al. 1999; Dale and Pourquie 2000; Pourquie 2000). Significantly, compound null mutants for Notch signaling genes such as Notch1 and Notch4, and presenilin1 and presenilin2 have defects in the cardiovascular system and somites similar to those described here for Foxc1; Foxc2 compound null mutants (Donoviel et al. 1999; Krebs et al. 2000). We therefore compared the expression of genes encoding members of the Notch signaling pathway in the paraxial mesoderm of wild-type and compound homozygous embryos (Fig. 6).

Notch1 is normally expressed in the anterior PSM with the highest level at S-2 (Fig. 6A; Conlon et al. 1995). In compound Foxc1; Foxc2 homozygotes, only very faint bands of expression of this gene can be detected in the regions corresponding to presumptive S-1 and S-2 (Fig. 6B). Mesp2 encodes a bHLH transcription factor and is expressed in a single band in the anterior half of S-2 (Fig. $6 \mathrm{E})$, in which it is thought to play a role in specifying anterior cell fate (Saga et al. 1997; Takahashi et al. 2000). A positive feedback loop exists between Mesp2 and 


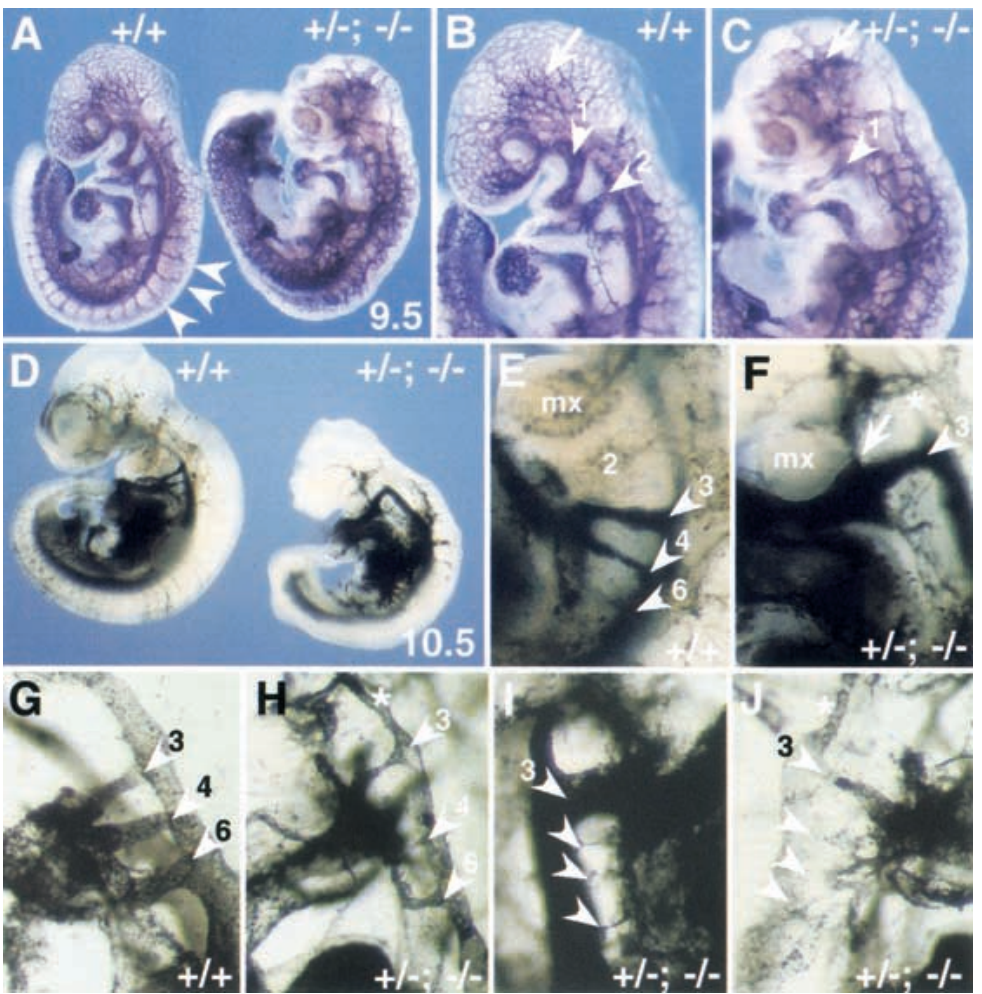

Figure 4. Cardiovascular abnormalities in compound Foxc1 ${ }^{+/}$; FoxC2 $2^{-/-}$mutants. Whole-mount PECAM-1 staining of wild-type embryo and $\mathrm{FoxC1}^{+/-}$; Foxc2 $2^{-1-}$ compound mutant at $9.5 \mathrm{dpc}$. $(A)$ and at higher magnification in $B$ and $C$. Even though somites have formed in the mutant (right), the intersomitic vessels are abnormal compared with wild type (arrowheads, left). In the mutant, capillary vessel formation in the head is also abnormal (arrow in $C$ ) and the first BA artery (arrowhead) is thin and the second BA artery is absent compared with wild type $(B) .(D-J)$ Ink-injected embryos at $10.5 \mathrm{dpc}$. In the wild type $(D)$ and at higher magnification in $E$, the first and second $\mathrm{BA}$ arteries have regressed and the third, fourth, and sixth BA arteries (arrowheads) have formed. In contrast, the mutant embryo $(D)$ and at higher magnification in $F$ has only a thick third BA artery (arrowhead) and an ectopic artery (arrow). $(G-J)$ Close-up of the BA arteries after clearing. In wild type $(G)$, left third, fourth and sixth BA arteries are clearly formed. Three different mutants have severe defects including $(H)$ left thin BA arteries (arrowheads); (I) right thick third BA artery and thin BA arteries (arrowheads) and $(J)$ right thin third BA artery and disorganized BA arteries (arrowhead). Note that the anterior dorsal aorta is thin in $F$, $H$, and $J$ (asterisk). (mx) Maxillary arch.

Notch1 and Mesp2 transcripts are not detected in Notch1-/- embryos and vice versa (Saga et al. 1997; Barrantes et al. 1999). Like Notch1, expression of Mesp2 is strongly down-regulated in compound homozygotes compared with the wild type (Fig. 6F). In addition, Mesp1, which is closely related to Mesp2 and is also expressed in S-2 (Saga et al. 1997), is down-regulated in compound Foxc1; Foxc2 homozygotes (Fig. 6C,D). No change in Mesp2 expression is seen in either Foxc1 ${ }^{-/-}$or Foxc2 ${ }^{-/-}$homozygotes (data not shown).

Expression of $L f n g$, which encodes a modulator of Notch receptor activity, normally proceeds in waves from the tail bud toward the anterior PSM (Aulehla and Johnson 1999). As each broad band reaches the anterior, it resolves into two tighter bands, the most anterior of which is about one-half a somite wide at S-1, with a sharp boundary adjacent to the posterior of S0 (Fig. 6G). In compound homozygotes, the tail bud expression of Lfng appears normal, but the usually sharp stripes of expression in the anterior PSM are reduced in intensity and are very diffuse (Fig. 6H). D111, which encodes one of the Notch ligands, is normally expressed throughout the PSM, but transcription is down-regulated in the anterior of S-1 and restricted to the posterior half of S-1. This restriction is thought to be regulated by both Mesp2dependent and independent pathways (Takahashi et al. 2000) and continues in the somites once they have formed (Fig. 6I). In compound homozygotes, D111 mRNA is present in the tailbud and PSM, but the anterior boundary is diffuse and expression in the somite region is completely down-regulated (Fig. 6J). Finally, Hes5, one of the target genes of the Notch signaling pathway, shows two stripes of expression in the anterior PSM of the wild type (Fig. 6K; Evrard et al. 1998). Again, in compound homozygotes, this pattern of striped expression is diffuse and down-regulated, although expression in the neural tube is unaffected (Fig. 6L).

\section{Foxc1 and Foxc2 are expressed in the presomitic mesoderm and somites of homozygous Dll1 mutant embryos.}

As described above, there is thought to be a feedback regulatory loop between Mesp2, Notch1, and Dll1 in the anterior PSM. To elucidate whether Foxc1 and Foxc2 participate in this feedback loop, we examined expression of the two genes in Dl11 homozygous mutants (Fig. 7). As shown in Figure 7A, Foxc1 is expressed in both the PSM and somites in Dll1 mutant embryos, but at a somewhat lower level compared with the wild type. In particular, the characteristic region with very high Foxc1 transcription is not seen in the anterior PSM. Furthermore, ectopic expression of Foxc1 is detected throughout the neural tube of Dll1 mutant embryo (Fig. 7C,E). We have found recently that zebrafish Foxc1 is expressed in some populations of sensory neurons (Topczewska et al. 2001) raising the possibility that it is also normally expressed in the neural tube of the mouse. Although this possibility has not been explored further here, it is likely that this population, undetected previously, is expanded in Dll1 mutant mouse embryos. Foxc2 mRNA is also detected in the PSM and somites of Dll1 homozygotes even though the level of transcription is again relatively lower than in the wild type (Fig. 7B). However, no ex- 

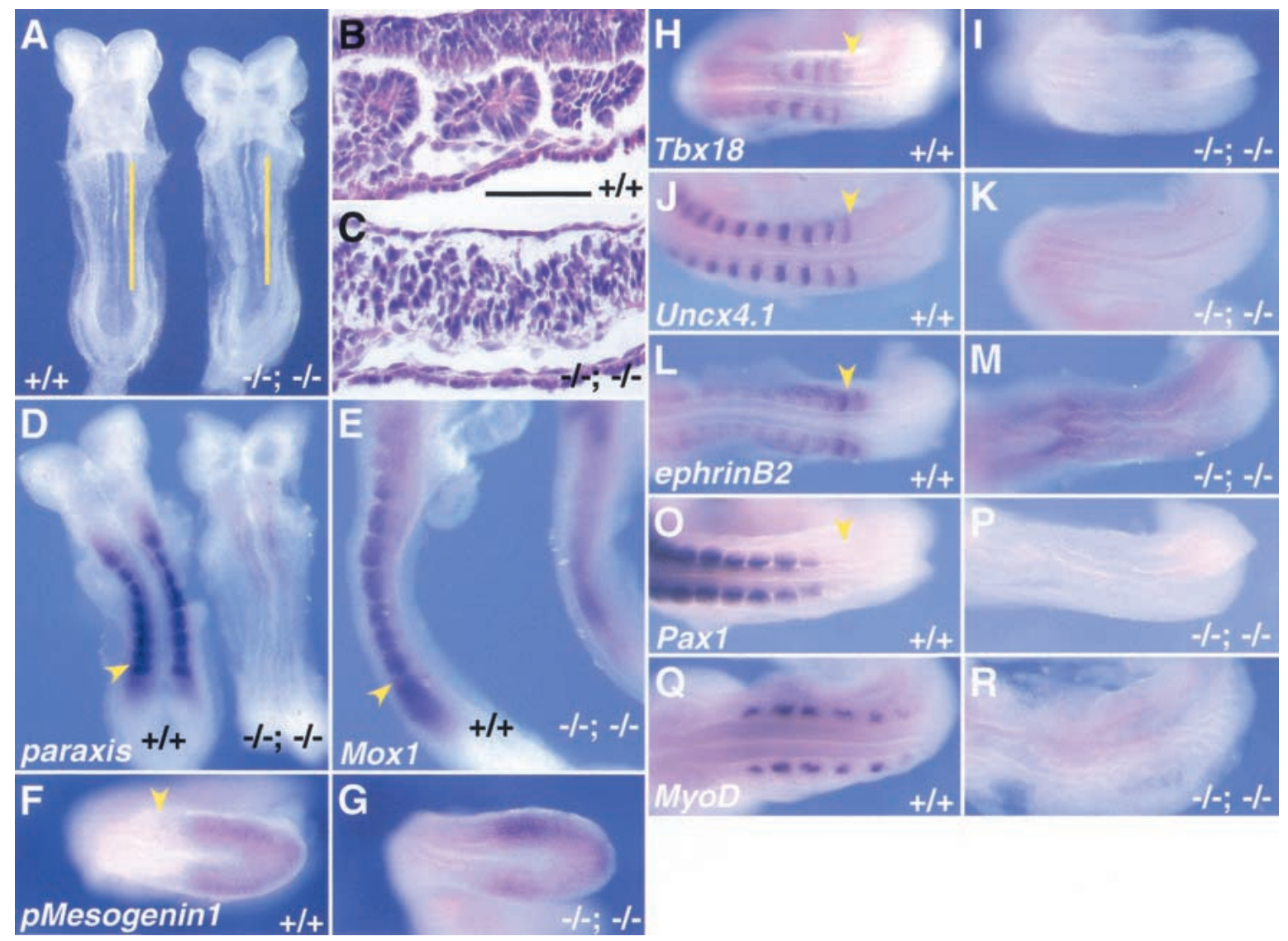

Figure 5. Complete absence of segmentation of the presomitic mesoderm and somites in compound $\mathrm{Foxc1}^{-/-}$; Foxc2 $2^{-/-}$mutant embryos. (A) Ventral view of wild-type (left) and compound homozygous embryo (right) at $8.5 \mathrm{dpc}$. The compound homozygote has no segmented somites, a kinked neural tube, and a small heart. $(B, C)$ Sagittal sections of embryos in $A$ at the level of yellow lines. The wild-type embryo has epithelialized somites $(B)$, but segmented, epithelialized somites are absent in the compound homozygous embryo, even though mesodermal cells are present $(C)$. Because of the level of the section, the neural tube is not shown in the compound homozygote. $(D-R)$ Whole-mount in situ hybridization of wild-type and compound homozygous embryos at 8.5-9.0 dpc. Arrows indicate the boundary between the newly formed somite (S1) and forming somite (SO). (D) In the compound homozygote (right), transcripts of paraxis are absent except low levels around the anterior neural tube. (E) Mox1 is expressed in the paraxial mesoderm of the presomitic and somite region of compound homozygote (right) as in the wild type (left). $(F, G)$ The level of transcription of pMesogenin 1 in the posterior PSM is unaffected in compound homozygote. $(H-K)$ Transcripts of Tbx18 and Uncx4.1, normally present in the anterior and posterior of somites, respectively $(H, J)$, are both absent in compound homozygote $(I, K)$. $(L, M)$ Expression of ephrinB2 is not restricted to the posterior half of the somites in compound homozygote $(M)$, compared with the wild type $(L) .(O, P) P a x 2$ is not transcribed in the region of presumptive somites of compound homozygote $(\mathrm{P})$ compared with the wild type $(\mathrm{O}) .(\mathrm{Q}, R) \mathrm{MyoD} \mathrm{mRNA}$, normally present in the differentiating myotome $(Q)$, is not detected in compound homozygote $(R)$. Scale bar, $100 \mu \mathrm{m}$.

pression is seen in the neural tube of Dll1 mutant embryo (Fig. 7G). Taken together, these data suggest that Foxc1 and Foxc2 are not obligatory components of the Notch1-Mesp2-Dll1 regulatory loop.

\section{Discussion}

Previous studies on the phenotype of Foxc1 and Foxc2 single homozygous null mutants, and compound heterozygotes led us to propose that the two closely related genes play similar, dose-dependent roles in the development of the cardiovascular, ocular, and genitourinary systems (Winnier et al. 1999; Kume et al. 2000b; Smith et al. 2000). A clear prediction of this hypothesis is that inactivation of all four alleles would result in more severe defects than when only two or three alleles are absent, because no alleles would be available to compensate for the loss of the others. The phenotype of compound null mutants would, therefore, finally reveal the earliest processes in which both genes normally play essential roles. In this study, we provide evidence to support this hypothesis, and thereby show, for the first time, that Foxc1 and Foxc2 are required synergistically for cardiovascular development and for somitogenesis, including formation of the most anterior somites. Furthermore, our data strongly suggest that during these processes, the two genes interact with the Notch signaling pathway. 


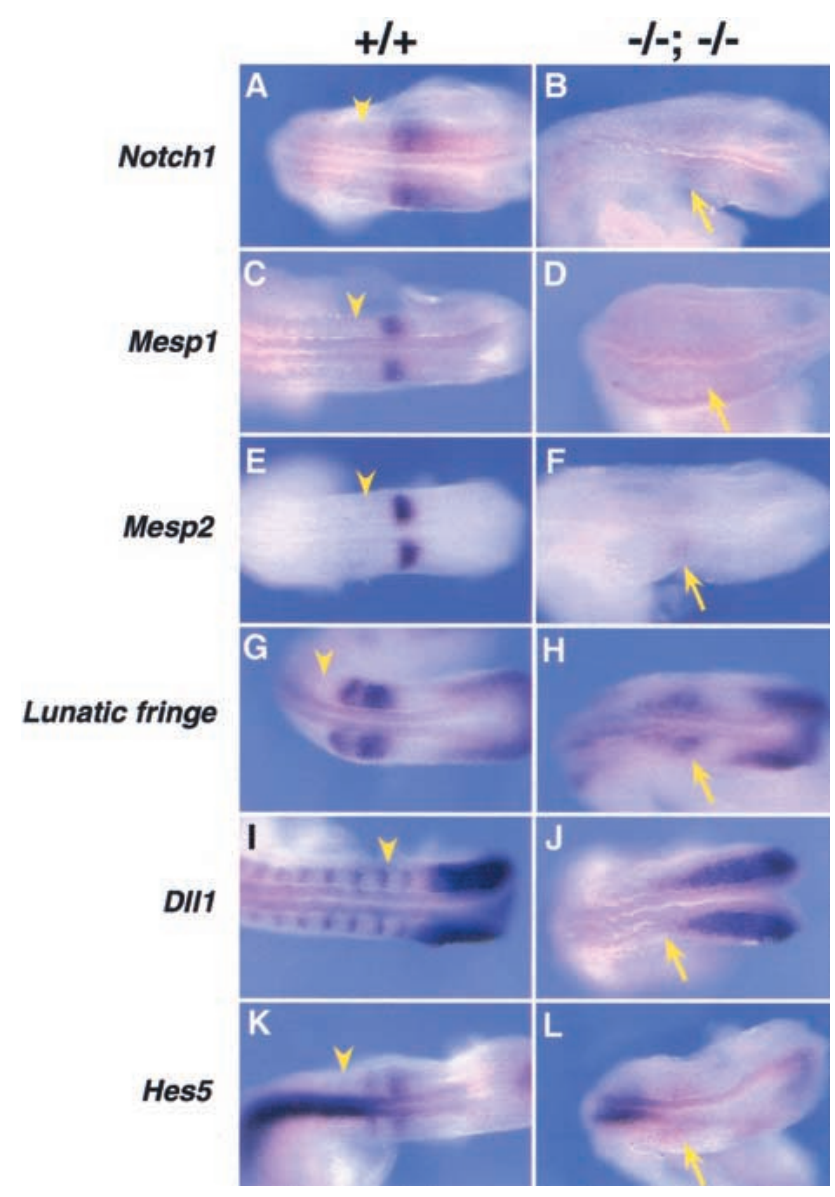

Figure 6. Expression of genes associated with the Notch signaling pathway in compound Foxc1 $1^{-1-}$; Foxc2 $2^{-/-}$embryos. Whole-mount in situ hybridization of wild-type and compound homozygous embryos at $9.0 \mathrm{dpc}$. Anterior is to the left and arrowheads indicate the boundary between the newly formed (S1) and forming somite (SO). (A-F) Compared with the wild type $(A, C, E)$, Notch1, Mesp1, and Mesp2 are all down-regulated in the anterior PSM (arrow) of compound homozygotes $(B, D, F$, respectively). $(G, H)$ The two sharp bands of Lunatic fringe expression in the anterior PSM of the wild type $(G)$ are diffuse (arrow) in compound homozygote $(H)$. $(I, J)$ The normally sharp boundary of Dl11 expression in the anterior PSM $(I)$ is diffuse in the compound mutant (arrow) and the striped expression pattern anterior of $\mathrm{S} 0$ is absent. $(K, L)$ The two stripes of Hes 5 expression in the anterior PSM of wild type $(K)$ are diffuse and down-regulated in compound homozygote $(L)$. Note normal expression in the neural tube.

\section{Roles of Foxc1/Foxc2 in segmentation and somite formation}

One of the most striking abnormalities of compound Foxc1; Foxc2 homozygotes is the complete lack of segmentation of the paraxial mesoderm, at least up to embryonic day (E)9.5. At the morphological level, this defect is manifest by the absence of either mature epithelial somites or paired mesodermal condensations (segments) either side of the midline. At the molecular level, there is complete absence of expression of paraxis and of marker genes normally expressed in the somites or their derivatives (Tbx18, Uncx4.1, Pax1, and MyoD). The cells flanking the notochord do appear to be correctly specified as paraxial mesoderm, however, as they express the homeobox gene, Mox1. Nevertheless, further quantitative analysis will be necessary to determine whether the relative allotment of mesoderm cells to paraxial, intermediate, and lateral cell fates is affected (see below).

Significantly, the defect in segmentation in compound Foxc1; Foxc2 mutants is apparent from the very beginning of somitogenesis. In contrast, most other mutations affecting somitogenesis allow relatively normal formation of anterior somites even though those in the trunk and tail are severely disrupted (Barrantes et al. 1999). The early lethality of the Foxc1; Foxc2 compound mutants does not allow us to determine whether posterior somites would be normal if these mutants continued to develop. However, it should be noted that in both single homozygous null mutants the anterior axial skeleton is more affected than the posterior skeleton /Gruneberg 1943; Iida et al. 1997; Winnier et al. 1997; Kume et al. 1998), raising the possibility that Foxc1 and Foxc2 are, in fact, only required for anterior somite development. Further experiments will be needed to test this hypothesis.

The absence of anterior somites points to an early and fundamental role for Foxc1 and Foxc2 in one or more of the processes involved in somite formation. Clues as to the precise steps disrupted come from the analysis of gene expression in the PSM of compound mutants, interpreted in the light of current general models for somitogenesis. As described in the Introduction, one of these models - the clock and wave front model-predicts that cells in the PSM undergo cyclical oscillations from one state to another. These oscillations are slowed and brought to a halt in response to a hypothetical wave front of maturation, leading to the establishment of a prepattern of presumptive somites in the anterior PSM. The pattern of expression of genes such as D111, Hes5, and Lfng in the PSM of the small number of compound Foxc1; Foxc2 mutants that we have been able to examine suggests that the cells do undergo cyclical oscillations from one state to another, driven by an internal clock. However, there is a distinct absence of sharp boundaries to the expression domains of these genes in the anterior PSM. There are two possible nonexclusive explanations for this diffuse anterior expression. One is a defect in the synchronization of oscillations between neighboring cells in the PSM, thought to be mediated by NotchDelta intercellular signaling. For example, the diffuse expression of Dll1 and Lfng in the anterior PSM, and the salt and pepper intermingling of cells with high and low expression (data not shown), is very similar to that seen for deltaC in zebrafish embryos with mutations in Notch pathway genes (Jiang et al. 2000). In zebrafish, this phenotype is thought to result from asynchrony between cell oscillations in the PSM. A second possibility, elaborated below, is that anterior PSM cells in Foxc1; Foxc2 mutants are unable to undergo maturation in response to the putative wave-front signal and to stabilize their expression patterns prior to beginning differentiation. 
Figure 7. Expression of Foxc1 and Foxc2 in homozygous Dll1 mutant embryos. $(A-C)$ Wholemount in situ hybridization of wild-type and Dll1 mutant embryos at $9.5 \mathrm{dpc}$. Arrows indicate the boundary between the newly formed (S1) and forming somite (SO). (A) Foxc1 is expressed in the PSM and somites of both wild-type (left) and D111 mutant embryos (right) but the normal domain of highest Foxc1 expression in the anterior PSM is not seen. (B) Foxc2 mRNA is detected in the PSM and somites of both wild-type (left) and Dll1 mutant embryo (right). $(C)$ Dorsal view of the tail region of wild-type (left) and Dll1 mutant (right) embryos. Scattered expression of Foxc1 is detected in the neural tube (arrow) of D111 mutant embryo. $(D-G)$ Section in situ hybridization of trunk region of wild-type and Dll1 mutant embryos at 9.5 dpc. Foxc1 mRNA is detected within the neural tube of the Dll1 mutant embryo $(E$, arrow), but not the wild type $(D) .(F, G)$ Expression of Foxc2 is not seen in the neural tube of either wild-type $(F)$ or Dl11 mutant $(G)$ embryos. (nt) Neural tube, (s) somite. Scale bar, $50 \mu \mathrm{m}$.

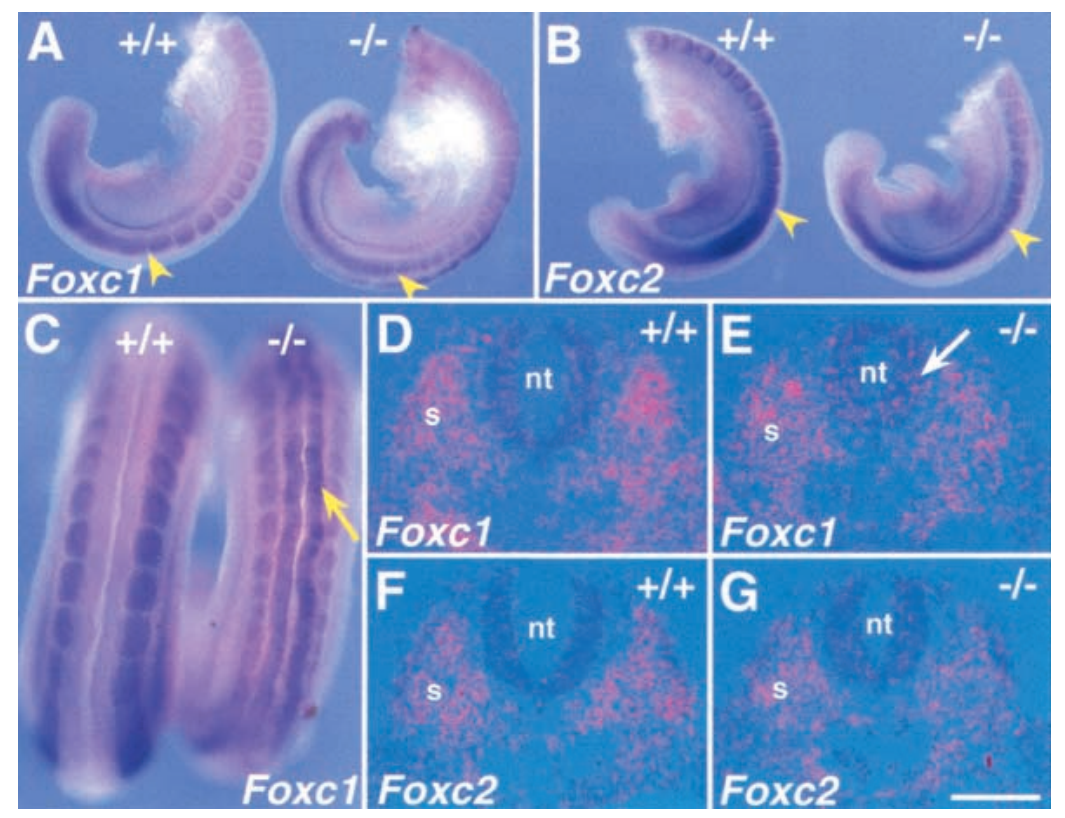

Recent genetic studies in the mouse have suggested that the establishment of distinct $\mathrm{A} / \mathrm{P}$ domains in the presumptive somites depends on Notch-Delta signaling between cells and an autoregulatory feedback loop involving the bHLH gene, Mesp2 (Takahashi et al. 2000). According to one current model, Mesp2 is both a downstream target of Notch1 signaling and an activator of Notch1 expression in the anterior domain of the presumptive somites. Moreover, Mesp2 activity is thought to promote the suppression of Dll1 expression in the anterior domain in response to Notch activation. The expression of both Mesp2 and the closely related gene, Mesp1, are strongly down-regulated in the PSM of Foxc1; Foxc2 compound mutants. However, it is unlikely that this is the result of a direct requirement for the two forkhead genes for the earliest initiation of Mesp1 and Mesp2 transcription, as the phenotype of Foxc1; Focx2 compound mutants is not as severe as that of Mesp1; Mesp2 compound mutants. The latter do not develop any embryonic mesoderm at all and have a very early failure in cardiac morphogenesis (Kitajima et al. 2000). The absence of both Mesp1 and Mesp2 expression, and the reduction of Dll1 expression in the anterior PSM of Foxc1; Foxc2 compound mutants may therefore be secondary to a primary failure in intracellular signaling in response to Notch activation, and/or to a primary block in Notch expression.

The failure to establish $\mathrm{A} / \mathrm{P}$ domains in the anterior PSM in Foxc1; Foxc2 compound mutants may subsequently disrupt the generation of a clear stripe of ephrinB2 expression and, consequently, intersomitic border formation. Alternatively, the abnormal ephrinB2 expression may reflect the failure to establish cell-cell interactions associated with ephrin/Eph signaling that normally restricts intermingling of cells.

Studies in the mouse have indicated that ps1 plays a role in up-regulating Dll1 expression in the posterior
PSM by a Mesp2-independent pathway (Takahashi et al. 2000). Significantly, the phenotype of ps1; ps2 compound null mutants resembles that of Foxc1; Foxc2 mutants in terms of the absence of a second branchial arch, a reduced first branchial arch, and anterior somite abnormalities (Donoviel et al. 1999). It is therefore possible that the Foxc1 and Foxc2 genes affect ps gene expression directly, or that both pairs of genes are required in parallel for the development of cephalic and paraxial mesoderm.

The absence of paraxis expression in the Foxc1; Foxc2 null mutants raises the possibility that the forkhead genes directly regulate the transcription of this gene. Evidence for this has come from studies with zebrafish embryos (Topczewska et al. 2001). However, absence of paraxis expression cannot be the primary defect in null mutants as there are several differences between the phenotype of Foxc1/Foxc2 and paraxis null mutants. For example, the latter still retain normal expression of Mesp2 and Notch pathway genes in the PSM, and paraxis mutants do form segmentation of the PSM (Burgess et al. 1996; Johnson et al. 2001).

In conclusion, our results support the idea that Foxc1 and Foxc2 are required either for Notch-dependent synchronization of oscillations in the PSM and /or for the competence of cells to respond to the putative wavefront maturation process proceeding posteriorly. For either or both reasons, they fail to establish $\mathrm{A}$ and $\mathrm{P}$ cell fates in the anterior PSM.

\section{Roles of Foxc1/2 in cardiovascular development}

Three major defects are seen in the early cardiovascular development of Foxc1; Foxc2 compound mutants. The first is a failure to remodel the primitive vascular plexi of the head, trunk, and yolk sac into a branched system of 
large and small blood vessels, even though endothelial cells and vascular smooth muscle cells apparently differentiate and associate normally. The second defect is in the development of the heart itself, which is smaller than normal and does not undergo complete morphogenesis. Finally, the number, size, and organization of the branchial arch arteries is very abnormal. Together, these abnormalities are probably the cause of the lethality of the compound mutants. The fact that the abnormalities are much more severe than in single homozygotes is evidence that Foxc1 and Foxc2 have similar, dose-dependent functions in cardiovascular as well as somite development. Moreover, one interesting finding is that there are phenotypic differences between $\mathrm{FoxC1}^{-1-}$; $\mathrm{FoxC2}^{+/-}$ and Foxc1 ${ }^{+/-}$; Foxc2 ${ }^{-/-}$embryos (Fig. 4; data not shown), suggesting that the functions of the two genes are not completely identical and/or that there are quantitiative differences in the level and onset of their expression. In the future, these possibilities will be explored by knocking in Foxc1 into the Foxc2 locus, and vice versa.

Previous studies have localized Foxc1 and Foxc2 transcripts in both endothelial cells and surrounding mesenchyme cells within the developing cardiovascular system, for example, in the branchial arteries, the outflow tract and the heart valves (Iida et al. 1997; Swiderski et al. 1999; Winnier et al. 1999). In this study, we also show by use of specific antibodies that the two proteins are present in the nuclei of both endothelial cells and smooth muscle cells of blood vessels in the embryo. It is therefore very likely that some aspects of the cardiovascular phenotype of the compound mutants are the direct result of abnormal gene expression within these cell populations. For example, there may be a primary failure in the formation of patent connections between arteries and veins in the embryo as described for ephrinB2 homozygous mutants (Wang et al. 1998; Adams et al. 1999). In addition, recent evidence suggests that the mutation in zebrafish gridlock, an ortholog of the HRT2 gene that is a downstream target for Notch signaling, perturbs the assembly of the junction between the paired lateral dorsal and the single medial dorsal aortae (Zhong et al. 2000).

However, we cannot rule out the possibility that some of the defects in the cardiovascular system are secondary to a failure to establish a vigorous blood circulation either within the embryo or between the embryo and the yolk sac. It is also possible that some of the defects in the branchial arch arteries are due to a primary deficiency in cephalic mesoderm in compound mutants. We have observed extensive apoptosis in the head mesenchyme (Fig. 2) which may be due to a failure of these cells to respond to local growth factors.

In the previous section, we argued that the defects in somitogenesis in compound Foxc1; Foxc2 mutants may be due to an interaction of Foxc1 and Foxc2 with the Notch pathway. Notch1; Notch4, and ps1; ps2 compound homozygotes have cardiovascular defects similar to those in Foxc1; Foxc2 compound homozygotes, including abnormal vascular remodeling (Donoviel et al. 1999; Krebs et al. 2000). This raises the possibility that
Foxc1 and Foxc2 also interact with the Notch signaling pathway in cardiovascular development.

\section{How do Foxc1/c2 function at the molecular level?}

Several possible molecular mechanisms can be proposed for how Foxc1 and Foxc2 function to regulate gene expression. One possibility is that the proteins interact with factors that are downstream of the Notch-Delta signaling pathway. For example, Groucho proteins form transcription repression complexes with bHLH transcription factors of the Hairy/Enhancer of split (Hes) class, and suppress expression of target genes in response to Notch activation (Fisher and Caudy 1998). Recent evidence has shown that Groucho can bind to two Fox proteins, Foxg1 (formerly Bf1) and Foxa2 (formerly Hnf3 $\beta$ ) (Wang et al. 2000; Yao et al. 2001) and similar kinds of interactions may occur with Foxc proteins.

Alternatively, Foxc1/c2 may play a role in opening up the chromatin structure of genes involved in paraxial mesoderm development. Such a role has been proposed previously for Foxa2 in the regulation of albumin gene during liver development (Cirillo and Zaret 1999; Zaret 1999). In support of this idea, overexpression of Foxc1 induces premature expression of paraxis in the early zebrafish embryos (Topczewska et al. 2001). Finally, several other mouse Fox genes are expressed early in different mesodermal populations and are required for their normal development. For example, Foxa1/2/3, Foxc1/c2, and Foxf1 are expressed in the axial, non-axial, and lateral plate mesoderm, respectively (Sasaki and Hogan 1993; Kume et al. 2000b; Mahlapuu et al. 2001). Early mesodermal expression of Foxc1/c2 overlaps with that of Foxb1 and Foxd2. Foxc1 and Foxc2 may therefore act first as regulators of the specification of mesodermal fates in concert with other Fox genes, and, second, as regulators of specific morphogenetic processes such as the segmentation of the PSM and remodeling of blood vessels.

\section{Materials and methods}

\section{Breeding mutant mice and genotyping}

Mice heterozygous for the null mutations, Foxc1/Mf1 ${ }^{1 a c Z}$ and Foxc2/Mfh $1^{\operatorname{tm} 1}$, and compound heterozygous mice for Foxc $1^{1 a c Z}$ and Foxc $2^{\text {tm } 1}$ were maintained by interbreeding and genotyping of mice and embryos was performed as described (Winnier et al. 1997; Kume et al. 1998, 2000b). Dll1 ${ }^{1 a c Z}$ heterozygous mice (Hrabe de Angelis et al. 1997; kindly provided by Dr. Achim Gossler, The Jackson Laboratory, Bar Harbor, ME) were maintained by interbreeding. Genotyping of heterozygous D111 1acz mice was performed by lacZ PCR and heterozygous and homozygous mutant embryos were distinguished by phenotype and intensity of lacZ staining. Noon on the day of plug is $0.5 \mathrm{dpc}$.

\section{Histological analysis and ink injection}

Histological analysis and ink injection into the embryonic heart were performed as described (Kume et al. 1998, 2000a,b; Win- 
nier et al. 1999). Immunohistochemistry on frozen sections was performed as described previously (Hogan et al. 1994).

\section{In situ hybridization}

Whole-mount and section in situ hybridization were performed essentially as described previously (Kume et al. 1998, 2000a,b). The following murine cDNAs were used as templates for $\left[\alpha-{ }^{35} \mathrm{~S}\right] \mathrm{UTP}$ or digoxygenin-labeled antisense RNA probes: paraxis $(0.5 \mathrm{~kb})$; Mox1 (0.5 kb); Notch1 $(0.4 \mathrm{~kb})$; Mesp1 (0.6 kb); Mesp2 (1.3 kb); Dll1 (2.1 kb); Lunatic fringe (1.2 kb); Hes5 (1.3 $\mathrm{kb})$; ephrinB2 (0.7 kb); pMesogenin1 (0.75 kb); Uncx4.1 (0.7 kb); Tbx18 (2 kb); MyoD (1.8 kb); Pax1 (0.3 and $0.7 \mathrm{~kb})$; Foxc1 (0.8 $\mathrm{kb})$; Foxc2 $(1.7 \mathrm{~kb})$.

\section{Generation of specific antibodies against Foxc1 and Foxc2}

Specific antibodies against Foxc1 and Foxc2 proteins were generated as described in the accompanying paper (Topczewska et al. 2001).

\section{Whole-mount immunohistochemistry}

Embryos and yolk sacs were fixed in $4 \%$ paraformaldehyde in PBS and subsequently stained with a monoclonal rat PECAM-1 antibody (clone MEC13.3; Pharmingen), or rabbit polyclonal antibodies against Foxc1 and Foxc2. Peroxidase-conjugated anti rat IgG (Jackson Immunoresearch) and peroxidase-conjugated anti rabbit IgG (Jackson Immunoresearch) were used for secondary antibodies. For $\alpha$-SMA immunostaining, peroxidase-conjugated anti- $\alpha$-SMA antibody (DAKO) was used.

\section{Preparation of total RNA and RT-PCR}

Total RNA was isolated from yolk sacs of wild-type embryos (ICR) at 9.5 dpc by use of TRIzol Reagent (Invitrogen) according to the manufacturer's protocol and subjected to reverse transcription with oligo (dT) primer and PCR amplification. The following primer pairs were used: Foxc1, 5'-GCGGAAATTG TAGGAGTTCCCTAG-3' (sense), 5'-TTTGGCATCTGGCTC ACAGG-3' (antisense); Foxc2, 5' -ACGAGTGCGGATTTGTA ACCAG-3' (sense), 5'-GTGTTTTTGGAATACCCCAGATGG $3^{\prime}$ (antisense); $\beta$-actin, 5' -GCTCGTCGTCGACAACGGCTC-3' (sense), 5'-CAAACATGATCTGGGTCATCTTCTC-3' (antisense).

\section{Culture of human aortic smooth muscle cells}

Human aortic smooth muscle cells were obtained from Clonetics and cultured according to the manufacturer's protocol.

\section{Acknowledgments}

We thank Drs. David Bader, Joey Barnett, Takashi Mikawa, and members of our laboratory for helpful discussions and Dr. Randy Johnson for critical reading of the manuscript. Probes were generously donated by Drs. Thomas Quertermous (paraxis), Christopher Wright (Mox1), Thomas Gridley (Notch1 and $M y o D)$, Yumiko Saga (Mesp1 and Mesp2), Achim Gossler (Dl11 and Hes5), Barbara Wold (pMesogenin1), Andreas Kispert (Tbx18), Peter Gruss (Uncx4.1), and Chen-Ming Fan (Pax1).

The publication costs of this article were defrayed in part by payment of page charges. This article must therefore be hereby marked "advertisement" in accordance with 18 USC section 1734 solely to indicate this fact.

\section{References}

Adams, R.H., Wilkinson, G.A., Weiss, C., Diella, F., Gale, N.W., Deutsch, U., Risau, W., and Klein, R. 1999. Roles of ephrinB ligands and $\mathrm{EphB}$ receptors in cardiovascular development: Demarcation of arterial/venous domains, vascular morphogenesis, and sprouting angiogenesis. Genes \& Dev. 13: 295306.

Aulehla, A. and Johnson, R.L. 1999. Dynamic expression of lunatic fringe suggests a link between notch signaling and an autonomous cellular oscillator driving somite segmentation. Dev. Biol. 207: 49-61.

Barrantes, I.B., Elia, A.J., Wunsch, K., De Angelis, M.H., Mak, T.W., Rossant, J., Conlon, R.A., Gossler, A., and de la Pompa, J.L. 1999. Interaction between Notch signaling and Lunatic fringe during somite boundary formation in the mouse. Curr. Biol. 9: 470-480.

Bergemann, A.D., Cheng, H.J., Brambilla, R., Klein, R., and Flanagan, J.G. 1995. ELF-2, a new member of the Eph ligand family, is segmentally expressed in mouse embryos in the region of the hindbrain and newly forming somites. Mol. Cell. Biol. 15: 4921-4929.

Burgess, R., Cserjesi, P., Ligon, K.L., and Olson, E.N. 1995. Paraxis: A basic helix-loop helix protein expressed in paraxial mesoderm and developing somites. Dev. Biol. 168: 296-306.

Burgess, R., Rawls, A., Brown, D., Bradley, A., and Olson, E.N. 1996. Requirement of the paraxis gene for somite formation and musculoskeletal patterning. Nature 384: 570-573.

Candia, A.F., Hu, J., Crosby, J., Lalley, P.A., Noden, D., Nadeau, J.H., and Wright, C.V. 1992. Mox-1 and Mox-2 define a novel homeobox gene subfamily and are differentially expressed during early mesodermal patterning in mouse embryos. Development 116: 1123-1136.

Cirillo, L.A. and Zaret, K.S. 1999. An early developmental transcription factor complex that is more stable on nucleosome core particles than on free DNA. Mol. Cell 4: 961-969.

Collier, J.R., McInerney, D., Schnell, S., Maini, P.K., Gavaghan, D.J., Houston, P., and Stern, C.D. 2000. A cell cycle model for somitogenesis: Mathematical formulation and numerical simulation. J. Theor. Biol. 207: 305-316.

Conlon, R.A., Reaume, A.G., and Rossant, J. 1995. Notch1 is required for the coordinate segmentation of somites. Development 121: 1533-1545.

Dale, K.J. and Pourquie, O. 2000. A clock-work somite. Bioessays 22: $72-83$.

Donoviel, D.B., Hadjantonakis, A.K., Ikeda, M., Zheng, H., Hyslop, P.S., and Bernstein, A. 1999. Mice lacking both presenilin genes exhibit early embryonic patterning defects. Genes \& Dev. 13: 2801-2810.

Durbin, L., Brennan, C., Shiomi, K., Cooke, J., Barrios, A., Shanmugalingam, S., Guthrie, B., Lindberg, R., and Holder, N. 1998. Eph signaling is required for segmentation and differentiation of the somites. Genes \& Dev. 12: 3096-3109.

Durbin, L., Sordino, P., Barrios, A., Gering, M., Thisse, C., Thisse, B., Brennan, C., Green, A., Wilson, S., and Holder, N. 2000. Anteroposterior patterning is required within segments for somite boundary formation in developing zebrafish. Development 127: 1703-1713.

Evrard, Y.A., Lun, Y., Aulehla, A., Gan, L., and Johnson, R.L. 1998. Lunatic fringe is an essential mediator of somite segmentation and patterning. Nature 394: 377-381.

Fang, J., Dagenais, S.L., Erickson, R.P., Arlt, M.F., Glynn, M.W., Gorski, J.L., Seaver, L.H., and Glover, T.W. 2000. Mutations in FOXC2 (MFH-1), a forkhead family transcription factor, are responsible for the hereditary Lymphedema-Distichiasis 
Syndrome. Am. J. Hum. Genet. 67: 1382-1388.

Fisher, A. and Caudy, M. 1998. The function of hairy-related bHLH repressor proteins in cell fate decisions. Bioessays 20: 298-306.

Forsberg, H., Crozet, F., and Brown, N.A. 1998. Waves of mouse Lunatic fringe expression, in four-hour cycles at two-hour intervals, precede somite boundary formation. Curr. Biol. 8: $1027-1030$.

Gossler, A. and Hrabe de Angelis, M. 1998. Somitogenesis. Curr. Top. Dev. Biol. 38: 225-287.

Gruneberg, H. 1943. Congenital hydrocephalus in the mouse: A case of spurious pleitropism. J. Genetics 45: 1-21.

Harvey, R.P. 1998. Heart development. Academic Press, San Diego, CA.

Hiemisch, H., Monaghan, A.P., Schutz, G., and Kaestner, K.H. 1998. Expression of the mouse Fkh1/Mf1 and Mfh1 genes in late gestation embryos is restricted to mesoderm derivatives. Mech. Dev. 73: 129-132.

Hogan, B.L.M., Beddington, R., Constantini, F., and Lacy, E. 1994. Manipulating the mouse embryo. Cold Spring Harbor Laboratory Press, Cold Spring Harbor, NY.

Holder, N. and Klein, R. 1999. Eph receptors and ephrins: Effectors of morphogenesis. Development 126: 2033-2044.

Hrabe de Angelis, M., McIntyre, J., 2nd, and Gossler, A. 1997. Maintenance of somite borders in mice requires the Delta homolog Dll1. Nature 386: 717-721.

Iida, K., Koseki, H., Kakinuma, H., Kato, N., Mizutani-Koseki, Y., Ohuchi, H., Yoshioka, H., Noji, S., Kawamura, K., Kataoka, Y., et al. 1997. Essential roles of the winged helix transcription factor MFH-1 in aortic arch patterning and skeletogenesis. Development 124: 4627-4638.

Jiang, Y.J., Smithers, L., and Lewis, J. 1998. Vertebrate segmentation: The clock is linked to Notch signaling. Curr. Biol. 8: R868-R871.

Jiang, Y.J., Aerne, B.L., Smithers, L., Haddon, C., Ish-Horowicz, D., and Lewis, J. 2000. Notch signaling and the synchronization of the somite segmentation clock. Nature 408: 475479.

Johnson, J., Rhee, J., Parsons, S.M., Brown, D., Olson, E.N., and Rawls, A. 2001. The anterior/posterior polarity of somites is disrupted in paraxis-deficient mice. Dev. Biol. 229: 176-187.

Jouve, C., Palmeirim, I., Henrique, D., Beckers, J., Gossler, A., Ish-Horowicz, D., and Pourquie, O. 2000. Notch signaling is required for cyclic expression of the hairy-like gene HES1 in the presomitic mesoderm. Development 127: 1421-1429.

Kaestner, K.H., Knochel, W., and Martinez, D.E. 2000. Unified nomenclature for the winged helix/forkhead transcription factors. Genes \& Dev. 14: 142-146.

Kidson, S.H., Kume, T., Deng, K., Winfrey, V., and Hogan, B.L.M. 1999. The forkhead/winged-helix gene, Mf1, is necessary for the normal development of the cornea and formation of the anterior chamber in the mouse eye. Dev. Biol. 211: 306-322.

Kitajima, S., Takagi, A., Inoue, T., and Saga, Y. 2000. MesP1 and MesP2 are essential for the development of cardiac mesoderm. Development 127: 3215-3226.

Kraus, F., Haenig, B., and Kispert, A. 2001. Cloning and expression analysis of the mouse T-box gene Tbx18. Mech. Dev. 100: 83-86.

Krebs, L.T., Xue, Y., Norton, C.R., Shutter, J.R., Maguire, M., Sundberg, J.P., Gallahan, D., Closson, V., Kitajewski, J., Callahan, R., et al. 2000. Notch signaling is essential for vascular morphogenesis in mice. Genes \& Dev. 14: 1343-1352.

Kume, T., Deng, K.Y., Winfrey, V., Gould, D.B., Walter, M.A., and Hogan, B.L.M. 1998. The forkhead/winged helix gene Mf1 is disrupted in the pleiotropic mouse mutation congen- ital hydrocephalus. Cell 93: 985-996.

Kume, T., Deng, K., and Hogan, B.L.M. 2000a. Minimal phenotype of mice homozygous for a null mutation in the forkhead/winged helix gene, Mf2. Mol. Cell. Biol. 20: 1419-1425. . 2000b. Murine forkhead/winged helix genes Foxc1 (Mf1) and Foxc2 (Mfh1) are required for the early organogenesis of the kidney and urinary tract. Development 127: 1387-1395.

Mahlapuu, M., Ormestad, M., Enerback, S., and Carlsson, P. 2001. The forkhead transcription factor Foxf1 is required for differentiation of extra-embryonic and lateral plate mesoderm. Development 128: 155-166.

Mansouri, A., Yokota, Y., Wehr, R., Copeland, N.G., Jenkins, N.A., and Gruss, P. 1997. Paired-related murine homeobox gene expressed in the developing sclerotome, kidney, and nervous system. Dev. Dyn. 210: 53-65.

Mears, A.J., Jordan, T., Mirzayans, F., Dubois, S., Kume, T., Parlee, M., Ritch, R., Koop, B., Kuo, W.L., Collins, W.L., et al. 1998. Mutations of the forkhead/winged-helix gene, FKHL7, in patients with Axenfeld-Rieger anomaly. Am. J. Hum. Genet. 63: 1316-1328.

Miura, N., Wanaka, A., Tohyama, M., and Tanaka, K. 1993. MFH-1, a new member of the fork head domain family, is expressed in developing mesenchyme. FEBS Lett. 326: 171176.

Nishimura, D.Y., Swiderski, R.E., Alward, W.L., Searby, C.C., Patil, S.R., Bennet, S.R., Kanis, A.B., Gastier, J.M., Stone, E.M., and Sheffield, V.C. 1998. The forkhead transcription factor gene FKHL7 is responsible for glaucoma phenotypes which map to 6p25. Nat. Genet. 19: 140-147.

Pourquie, O. 2000. Segmentation of the paraxial mesoderm and vertebrate somitogenesis. Curr. Top. Dev. Biol. 47: 81-105.

Saga, Y., Hata, N., Koseki, H., and Taketo, M.M. 1997. Mesp2: A novel mouse gene expressed in the presegmented mesoderm and essential for segmentation initiation. Genes \& Dev. 11: 1827-1839.

Sasaki, H. and Hogan, B.L.M. 1993. Differential expression of multiple fork head related genes during gastrulation and axial pattern formation in the mouse embryo. Development 118: 47-59.

Schnell, S. and Maini, P.K. 2000. Clock and induction model for somitogenesis. Dev. Dyn. 217: 415-420.

Smith, R.S., Zabaleta, A., Kume, T., Savinova, O.V., Kidson, S.H., Martin, J.E., Nishimura, D.Y., Alward, W.L., Hogan, B.L.M., and John, S.W. 2000. Haploinsufficiency of the transcription factors FOXC1 and FOXC2 results in aberrant ocular development. Hum. Mol. Genet. 9: 1021-1032.

Srivastava, D. 2001. Genetic assembly of the heart: Implications for congenital heart disease. Annu. Rev. Physiol. 63: 451469.

Srivastava, D. and Olson, E.N. 2000. A genetic blueprint for cardiac development. Nature 407: 221-226.

Swiderski, R.E., Reiter, R.S., Nishimura, D.Y., Alward, W.L., Kalenak, J.W., Searby, C.S., Stone, E.M., Sheffield, V.C., and Lin, J.J. 1999. Expression of the Mf1 gene in developing mouse hearts: Implication in the development of human congenital heart defects. Dev. Dyn 216: 16-27.

Takahashi, Y., Koizumi, K., Takagi, A., Kitajima, S., Inoue, T., Koseki, H., and Saga, Y. 2000. Mesp2 initiates somite segmentation through the Notch signaling pathway. Nat. Genet. 25: 390-396.

Topczewska, J.M., Topczewski, J., Shostak, A., Kume, T., Sdnica-Krezel, L., and Hogan, B.L.M. 2001. The winged helix transcription factor Foxcla is essential for somitogenesis in zebrafish. Genes \& Dev. 15: 2483-2493 (this issue).

Wang, H.U., Chen, Z.F., and Anderson, D.J. 1998. Molecular distinction and angiogenic interaction between embryonic 
Kume et al.

arteries and veins revealed by ephrin-B2 and its receptor EphB4. Cell 93: 741-753.

Wang, J.C., Waltner-Law, M., Yamada, K., Osawa, H., Stifani, S., and Granner, D.K. 2000. Transducin-like enhancer of split proteins, the human homologs of Drosophila groucho, interact with hepatic nuclear factor $3 \beta$. J. Biol. Chem. 275: 18418-18423.

Winnier, G.E., Hargett, L., and Hogan, B.L.M. 1997. The winged helix transcription factor MFH1 is required for proliferation and patterning of paraxial mesoderm in the mouse embryo. Genes \& Dev. 11: 926-940.

Winnier, G.E., Kume, T., Deng, K., Rogers, R., Bundy, J., Raines, C., Walter, M.A., Hogan, B.L.M., and Conway, S.J. 1999. Roles for the winged helix transcription factors MF1 and MFH1 in cardiovascular development revealed by nonallelic noncomplementation of null alleles Dev. Biol. 213: 418-431.

Yao, J., Lai, E., and Stifani, S. 2001. The winged-helix protein Brain factor 1 interacts with Groucho and Hes proteins to repress transcription. Mol. Cell. Biol. 21: 1962-1972.

Yoon, J.K. and Wold, B. 2000. The bHLH regulator pMesogenin1 is required for maturation and segmentation of paraxial mesoderm. Genes \& Dev. 14: 3204-3214.

Zaret, K. 1999. Developmental competence of the gut endoderm: Genetic potentiation by GATA and HNF3/fork head proteins. Dev. Biol. 209: 1-10.

Zhong, T.P., Rosenberg, M., Mohideen, M.A., Weinstein, B., and Fishman, M.C. 2000. gridlock, an HLH gene required for assembly of the aorta in zebrafish. Science 287: 1820-1824. 


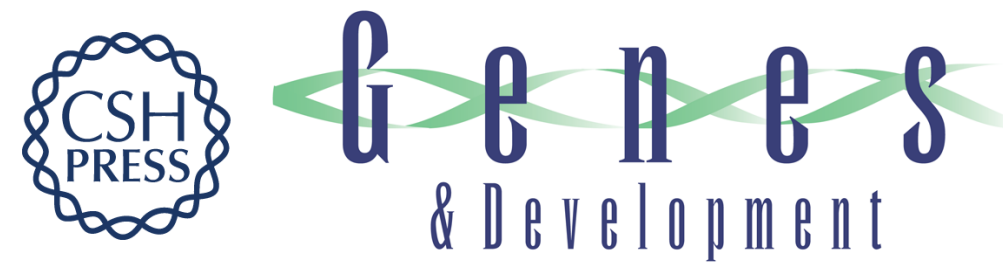

\section{The murine winged helix transcription factors, Foxc1 and Foxc2, are both required for cardiovascular development and somitogenesis}

Tsutomu Kume, HaiYan Jiang, Jolanta M. Topczewska, et al.

Genes Dev. 2001, 15:

Access the most recent version at doi:10.1101/gad.907301

References This article cites 58 articles, 24 of which can be accessed free at:

http://genesdev.cshlp.org/content/15/18/2470.full.html\#ref-list-1

License

Email Alerting Receive free email alerts when new articles cite this article - sign up in the box at the top Service right corner of the article or click here.

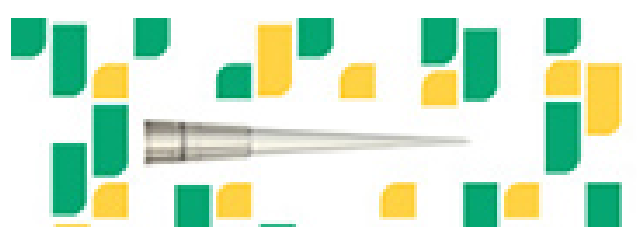

Focused on your science. 